\title{
The packaging structure exploration of ready-to-eat kebab products for street vendors (Case Study: Royal Kebab, Kebab Franchise)
}

\author{
S.A. Putri, A.S. Pawestri \& A.N. Hutami \\ Telkom University, Bandung, Indonesia
}

\begin{abstract}
Market competition is growing rapidly especially in the field of food, and many producers are competing with each other to grab the attention of potential consumers, as has been done by kebab street vendors. Therefore, it is necessary to explore new packaging design as a recommendation for ready-to-eat kebab products sold by street vendor. In the packaging design process, it is necessary to analyze the products that need to be packaged. This analysis is conducted to determine the product character and design requirements as a reference in the packaging design process. This needs to be done so that the resulting packaging design recommendations match the packaging needs of Kebab products. This packaging design recommendation aims to achieve the ideal packaging character, namely packaging that can increase the attractiveness of the products being sold, make it easier for consumers to consume the products contained therein, and can facilitate the packaging process.
\end{abstract}

Keywords: packaging, packaging system, design exploration, street vendor packaging, kebab packaging

\section{INTRODUCTION}

Fast food has long been recognized by the Indonesian people. The need for a food serving system that does not take time, both in the processing process and the consumption of the product, has led to innovations in fast food outlets that offer increasingly diverse product variants with competitive quality and prices. One of the most popular fast-food products is the kebab. This type of food originating from the Middle East is quite popular in Indonesia, of course, by adjusting the original taste to the tastes of the Indonesian people. This kebab product has been circulating with various brands in the market, ranging from restaurant class to street food vendors. One of the street kebab brands is Royal Kebab. Royal Kebab is a kebab franchise, specialized in street food-style kebabs and sold out of a cart.

Like any other street kebab vendors, owners of Royal Kebab reduce packaging costs by using simple packaging to make their products affordable for their customers. This is why the packaging that they are using right now still has room for developments, especially since the competition among similar brands and products is tight. packaging development is not only about protecting the product but also plays an important role in increasing the selling value of the product. In the packaging design process, it is necessary to analyze the products to be packaged. This analysis is carried out to determine the character of the product and design needs as a reference in the packaging design process. This needs to be done so that the resulting packaging design recommendations match the packaging needs of Kebab products. This packaging design recommendation aims to achieve the ideal packaging character, which is packaging that can increase the attractiveness of the products being sold, make it easier for consumers to consume the products contained therein, and can facilitate the packaging process. 


\section{RESEARCH METHOD}

According to Klimchuk and Krasovec (2012), the packaging design's function is to visually communicate product differences. Packaging design becomes a brand's promotional vehicle, highlighting its position on the shelf. Therefore, a well-designed packaging informed the consumer about the product, increasing product value (especially from visual aspects), and also influencing consumers to buy. Packaging design can be done through several systematic arrangements. Klimchuk and Krasovec (2012) also describes the seven phases of the packaging design process as follows:

Phase 1: Research and analysis (or observation, immersion, and discovery)

Phase 2: Preliminary design (or design strategy)

Phase 3: Design development (or creative development)

Phase 4: Design refinement

Phase 5: Design finalization and preproduction

Phase 6: Production

Phase 7: Brand activation

In this paper, the phases to be applied are Phases 1-3 with the assumption that the design made is a concept that has not been realized in physical form.

The research process begins by collecting data about the character of kebab products. In this research, the street vendor used as a case study is Royal Kebab. Located on Jalan Sukabirus, Telkom University Area, Royal Kebab has been operating since 2017 with non-franchise ownership status. The data is then analyzed and supported by literature studies, seen from the material and packaging structure aspects. The results of the analysis in the form of design requirements (design requirements) are then used as the basis for designing kebab packaging. The alternative design is then supported by material exploration and a packaging prototype is made. The results of the design and exploration are then used as packaging recommendations.

\section{RESULT AND DISCUSSION}

The first phase in packaging design is research and analysis (or observation, immersion, and discovery). In this study, research and analysis were carried out to obtain an overview of packaging needs and the possible materials that will be used in the packaging. Sources of field information are obtained from Royal Kebab products. The products in "Royal Kebab" are packaged using oil paper that has been printed with the words "Royal Kebab". The kebab that has been packaged using wax paper is then given adhesive in several parts to prevent it from falling apart. The kebab which has been wrapped in wax paper is then put into a paper bag. The wrapping process is done in a folded manner, so it takes quite a while when there are quite a lot of orders.

The kebabs in "Royal Kebab" come in various sizes, from jumbo to small. All kebabs are packaged using the same size wax paper and paper bag. For kebab products with additional toppings such as eggs and cheese, use extra wax paper to ensure that the oil does not leak out. To enjoy the product, the packaging is torn randomly to release the product. There are no guidelines to open the product.

The next phase in packaging design is the preliminary design (or design strategy). Based on the findings from the character of the existing "Royal Kebab" packaging, packaging development must be able to meet the following needs:

1. Packaging that can speed up the seller during the packaging process.

2. Packaging that can facilitate consumers when consuming these kebabs.

3. Packaging that no longer produces a lot of waste.

This strategy is then used as the basis for Phase 3: Design development (or creative development). To facilitate the packaging process, the new packaging design must be able to lock the product 

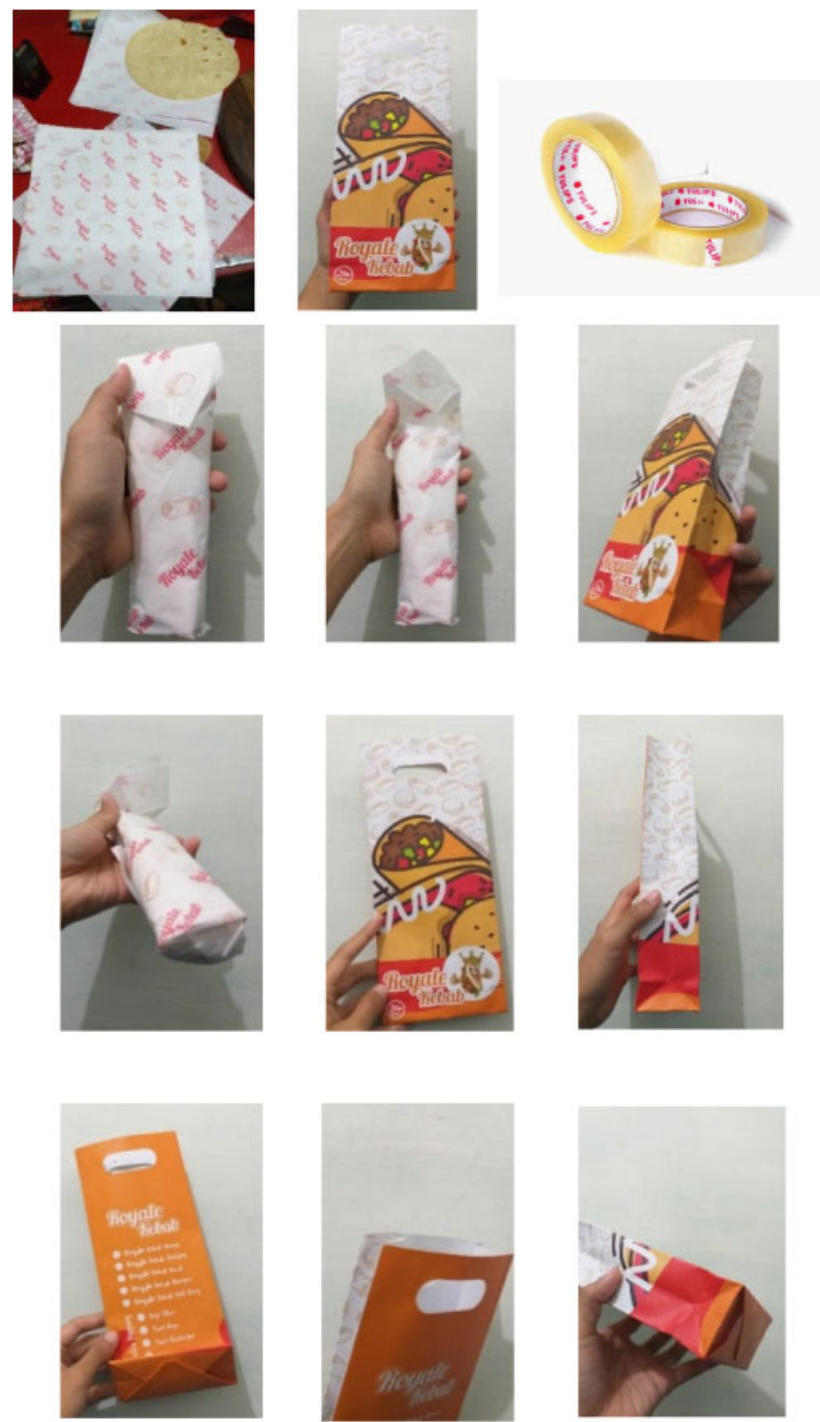

Figure 1. Current packaging of Royal Kebab (2019).

securely even without the folding process as has been done with the existing product. In the new packaging design, the shape chosen is a hexagon or hexagon as the main shape.

The choice of this shape is so that it has a better grip than the curved and flat surface of the existing packaging. For the bottom of the package, a fold lock system is used at the bottom of the package. This lock system is easy to open, but it can hold the product in the package. The lock on the top is tied using a rope as shown below. This lock can also act as a temporary handle of the packaging. The selection of a strap in the form of a strap is used to give a personal impression while making it easier to attach the tag label if needed.

For the second packaging strategy point, a product opening mechanism is created that helps consumers to open packages neatly. A neat packaging opening not only supports the aesthetics of the product when it is enjoyed by consumers but also allows the product brand to be better displayed. In the new packaging design results, the product operational mechanism is carried out by opening 

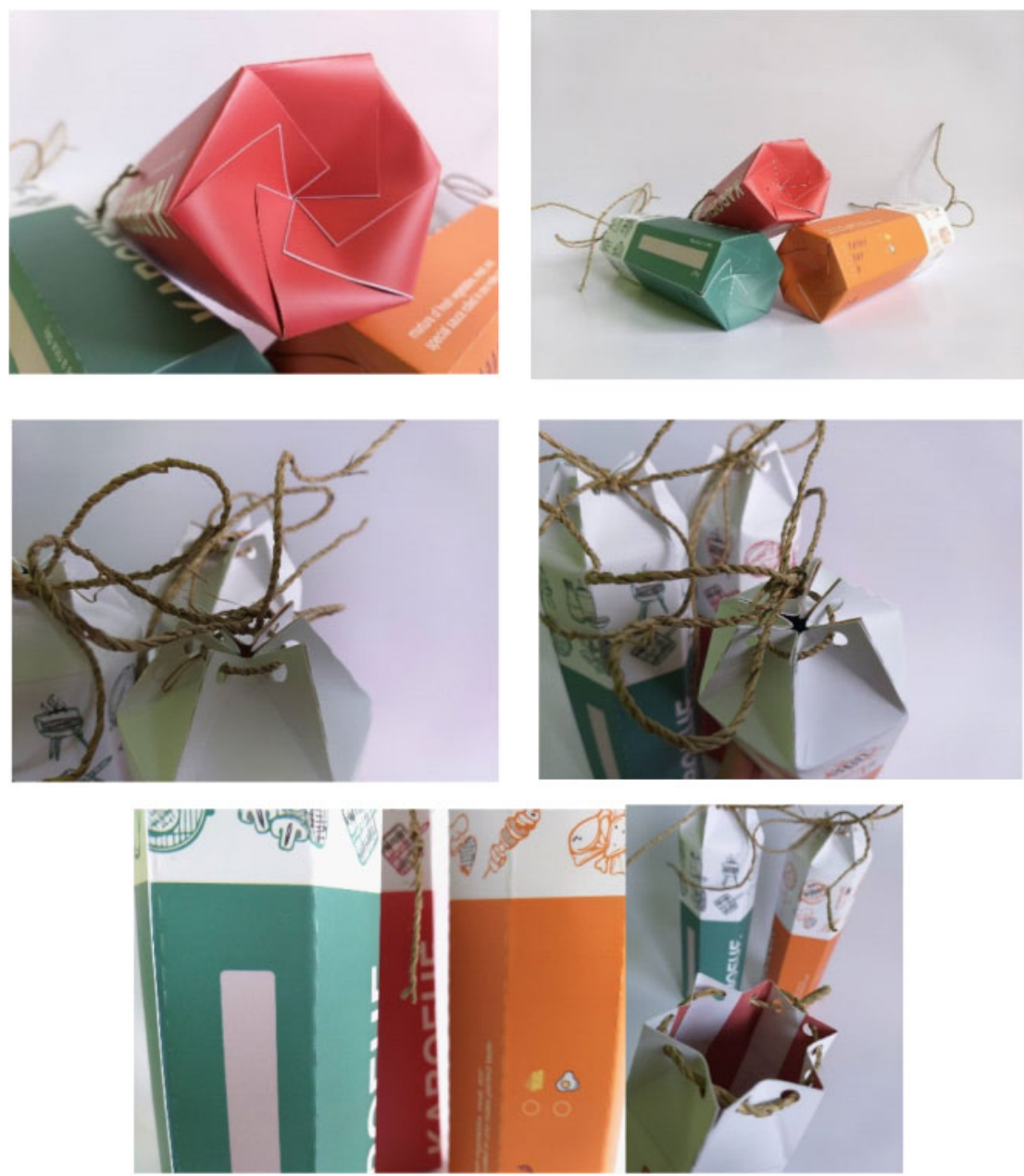

Figure 2. Kebab packaging system exploration result. (Source: Putri, Prawestri, and Hutami 2020).

the rope on the top of the package. After opening, the package can be torn according to the dotted line provided. Then kebab will immediately be enjoyed by consumers.

To minimize additional paper layers that have the potential to leave more waste, the packaging material uses laminated food-grade paper which is able to withstand oil.

The way the packaging works is as follows. The kebab that will be packed will be directly put into the package through the top, without being coated with warp paper anymore, because this package has been laminated so that it is oil resistant. The shape and appearance of the packaging will remain intact and maintain its freshness even if the kebab is not coated with additional wrapping paper.

However, further studies and research are needed to test this design result in its actual purposes. The design needs to proceed further through Phase 4: Design refinement, Phase 5: Design finalization and preproduction, Phase 6: Production, until Phase 7: Brand activation.

\section{CONCLUSION}

Packaging is a container to protect an item in order to keep it safe, intact, and also attract potential customers. Packaging can also be a medium of communication between producers and potential 
consumers as well as a medium for promoting a product. So that the packaging needs to include information that must be known by potential consumers.

The material for making packaging must be safe. It is safe to protect goods when sending it to the hands of consumers and safe for consumers when consuming a food product. By re-designing this kebab package, we improved a few things from the previous kebab packaging. We tried to solve the problems in kebab packaging, such as the difficulty of consumers enjoying kebabs, the length of the kebab packaging process, to the less attractive form of kebab packaging.

However, further studies are needed to make sure the newly designed packaging is suitable for the market. These further studies include the street vendor experiences using the new packaging and how the consumers respond to the packaging. The result will be determined if the packaging still needs to be developed or ready to be released in the market.

This re-design process, hopefully, it will inspire packaging for street vendor kebabs, help overcome the packaging problems faced, and of course, it can make consumer appeal to kebab products increase.

\section{ACKNOWLEDGMENT}

Special acknowledgments for royal kebab owners who are willing to cooperate during the data collection process.

\section{REFERENCES}

Creswell, John W. 2010. Research Design: Pendekatan Kualitatif, Kuantitatif, dan Mixed. (diterjemahkan oleh: Achmad Fawaid). Yogyakarta: Pustaka Pelajar.

Cuffaro, Daniel. 2006. The Industrial Design. Rockport Publishers: Beverly. Mayall, William H. (1979). Principles In Design. Design Council: London.

Ellicot, C. and Roncarelli, S. 2010. Packaging Essentials. Massachusetts: Rockport.

Klimchuk, M. R. and Krasovec, S. A. 2012. Packaging design: Successful product branding from concept to shelf (second edition). Hoboken, NJ: J. Wiley \& Sons.

Moleong, Lexy J. 2007. Metode Penelitian Kualitatif. PT Remaja Rosdakarya: Bandung.

Purwandi, Lilik. 2016. INDONESIA 2020:The Urban Middle-Class Millennials. Avara research center: Indonesia.

Sugiyono. 2015. Metode Penelitian dan Pengembangan. Penerbit Alfabeta: Bandung.

Ulrich, Karl T. Eppinger, Steven, D. 1995. Product Design and Development. McGraw-Hill Book Co.: Singapore. 